\title{
Researching natural disaster preparedness through health behavioral change models
}

\begin{abstract}
There have been an increasing number of studies conducted on community preparedness, particularly on changing individual health behaviors in ways that minimizes individual risk to cope with the stress of a natural disaster. A variety of behavioral change theories and models used by disaster academics scrutinize the manner in which individual behavior is sought and transformed into disaster preparedness. This reflects the lack of knowledge about how these models identify certain behaviors regarding natural disaster preparation. This article seeks to address this lack of knowledge. It presents a set of health behavioral change models that can be used by scholars to comprehend variation in the nature and extent of individual disaster preparedness. The purpose of this study is to provide a review of the existing models on the subject, and also to present a comparative analysis of the models that may contribute to ways of understanding the investigation on natural disaster preparedness behaviors.
\end{abstract}

Keyword: Natural disaster; Disaster preparedness; Disaster risk reduction; Health behavioral change models 